\title{
A FORMAÇÃO NO TEMPO E NO ESPAÇO DA INTERNET DAS COISAS*
}

\author{
VÂNia Gomes Zuin ${ }^{1}$ \\ Antônio Álvaro SoAres Zuin ${ }^{2}$
}

RESUMO: A Internet das Coisas tem revolucionado a forma de produção e reprodução do conhecimento. Trata-se de um tipo de interface comunicacional entre humanos, máquinas e objetos que, ao fundir os mundos material e informacional, suscita as seguintes questóes: (1) a possibilidade de obtenção imediata de quaisquer informaçóes implicaria na produção do pensamento crítico, em uma espécie de relação causaefeito?; (2) se é possível acessar as informaçóes em quaisquer tempo e espaço, quais seriam as transformaçóes decorrentes no processo formativo dos alunos e dos professores? Justamente essas questóes motivaram os autores do artigo a elaborar o seguinte objetivo: refletir criticamente sobre a revitalização do conceito de formaçáo (Bildung) na temporalidade e localidade da Internet das Coisas.

Palavras-chave: Internet das Coisas. Formação. Semiformação. Tecnologia. Theodor W. Adorno. Escola sem Partido.

\section{THE FORMATION IN TIME AND SPACE OF THE INTERNET OF THINGS}

ABSTRACT: The Internet of Things is revolutionizing the way of production and reproduction of knowledge. This is a type of communicational interface between humans, machines and objects which fuse the material and informational worlds and raises the following questions: (1) the possibility to immediately obtain any information would result in the production of critical thinking through

\footnotetext{
*Este artigo é produto de pesquisas realizadas pelos autores na condiçâo de professores-visitantes na Universidade de York, Inglaterra, de 2014 a 2015, junto aos departamentos de Química e Educação, respectivamente. Os autores também agradecem os apoios recebidos da Fundação de Amparo à Pesquisa do Estado de São Paulo (FAPESP) (Projeto de Pesquisa Regular, Bolsa Pesquisa no Exterior), da Coordenação de Aperfeiçoamento de Pessoal de Nível Superior (CAPES) (Estágio Sênior) e do Conselho Nacional de Desenvolvimento Científico e Tecnológico (CNPq) (Bolsas de Produtividade em Pesquisa). ${ }^{1}$ Universidade Federal de São Carlos, Programas de Pós-Graduação em Educação e em Química São Carlos (SP), Brasil. E-mail: vaniaz@ufscar.br

${ }^{2}$ Universidade Federal de São Carlos, Departamento de Educação - São Carlos (SP), Brasil.

E-mail: dazu@ufscar.br
}

DOI: $10.1590 / E S 0101-73302016167198$ 
a kind of cause-effect relationship ?; (2) if you can access the information at any time and space, what would be the changes related to the formativ process of students and teachers? Precisely these issues have motivated the authors of the article to draw up the following objective: to critically reflect on the revitalization of the concept of formation (Bildung) in the Internet of Things' time and spaciality.

Keywords: Internet of Things. Formation. Semiformation. Technology. Theodor W. Adorno. School without Party.

\section{LA FORMATION DANS LE TEMPS ET L'ESPACE DE L'INTERNET DES OBJETS}

RESUMÉ: L'Internet des objets a révolutionné la façon de la production et de la reproduction de la connaissance. Ce type d'interface de communication entre les humains, les machines et les objets, de fusionner les mondes matériels et d'information, soulève les questions suivantes: 1) La possibilité d'obtenir immédiatement toute information se traduirait par la production de la pensée critique, par une sorte de relation de cause à effet?; 2) Si vous pouvez accéder à l'information à tout moment et l'espace, quels sont les changements qui en résultent dans le processus de formation des étudiants et des enseignants? Précisément ces questions ont motivé les auteurs de l'article à élaborer l'objectif suivant: une réflexion critique sur la revitalisation du concept de formation (bildung) dans le temps et l'espace de l'Internet des objets.

Mots-clés: Internet des Objets. Formation. Semiformation. Technologie. Theodor W. Adorno. École Sans Parti.

\section{Introdução}

$\mathrm{H}$

á um conto de Jorge Luis Borges (1899-1986), intitulado "Funes, o memorioso", que ilustra metaforicamente o modo como o atual espírito objetivo do tempo, de uma cultura, se materializa nas relaçóes estabelecidas entre os seres humanos e os objetos por eles produzidos. Irineu Funes, o emblemático protagonista do conto de Borges, era um indivíduo que "olhava sem ver, ouvia sem ouvir, esquecia-se de tudo, de quase tudo" (BORGES, 2000, p. 543). Certo dia, Funes sofre um acidente e se aleija. Mas a deficiência física foi compensada pela aquisição de uma capacidade mnemônica sobre-humana que simplesmente o fazia ser incapaz de esquecer.

As lembranças de Funes eram tão prodigiosas, que "o presente era quase intolerável de tão rico e tão nítido, e também as memórias mais antigas e triviais" (BORGES, 2000, p. 543). A torrente de estímulos audiovisuais percebida por 
Funes, e que se convertia em lembranças-imagens contínuas e acumulativas, era táo avassaladora e prazerosa, que, quando ele dormia, sofria uma tormenta indescritível, pois nesse momento "se distraía do mundo" (BORGES, 2000, p. 545). Apesar de ter aprendido facilmente as línguas inglesa, francesa e portuguesa, o narrador do conto suspeitava que Funes não fosse capaz de pensar, pois "pensar é esquecer diferenças, é generalizar, é abstrair. No abarrotado mundo de Funes não havia senão pormenores, quase imediatos" (BORGES, 2000, p. 545). Assim, a capacidade mnemônica de Funes era tamanha, que ele dizia o seguinte de si: "mais recordaçóes tenho eu sozinho que as que tiveram todos os homens desde que o mundo é mundo (...) minha memória, senhor, é como despejadouro de lixos" (BORGES, 2000, p. 544).

Esse conto de Borges foi escrito em 1942. Contudo, é interessante destacar o modo como se transforma em chave de leitura em tempos nos quais o esquecimento se torna algo praticamente impossível de acontecer. $\mathrm{Na}$ sociedade da chamada revolução microeletrônica, a memória digital possibilita-nos lembrar de qualquer assunto em qualquer tempo. No atual abarrotado mundo de estímulos audiovisuais, os pormenores imediatos adquirem poder na mesma proporção em que se arrefece a força do pensamento que procura relacioná-los com o objetivo de se compreender a história das relações humanas responsáveis por suas tonalidades tão sobressalentes e sedutoras. $\mathrm{O}$ enfraquecimento dessa compreensão precisa ser investigado no contexto da denominada cultura digital, cujas formas objetivas se disseminam em praticamente todas as relaçóes sociais, sejam as do trabalho ou as do chamado tempo livre, que se assemelham cada vez mais. O gradativo desaparecimento das fronteiras entre as esferas do trabalho e do tempo livre fundamenta-se no desenvolvimento das forças produtivas, notadamente as de ordem tecnológica, que fazem com que, para usar uma expressão atual, os indivíduos permaneçam conectados sem quaisquer tipos de rupturas espaçotemporais.

É nessa sociedade que se torna uma realidade irreversível o recrudescimento da denominada Internet das Coisas, ou seja, um tipo de interface comunicacional entre humanos, máquinas e objetos que já revoluciona a forma de produção, reprodução e uso do conhecimento, o que suscita a presença das seguintes questóes:

1. a possibilidade de obtenção imediata de quaisquer informações implicaria necessariamente na promoçáo do pensamento crítico, em uma espécie de relação causa-efeito?;

2. se é possível acessar as informaçóes em quaisquer tempo e espaço, quais seriam as transformaçóes decorrentes no processo formativo dos alunos e dos professores?

Justamente essas questóes motivaram os autores do artigo a elaborarem o seguinte objetivo: refletir criticamente sobre a revitalização do conceito de formaçáo (Bildung) na temporalidade e espacialidade da Internet das Coisas. Para 
que o objetivo possa ser cumprido, é preciso primeiramente analisar as características da formação antes da revolução microeletrônica.

\section{Formação, duração, matéria e memória}

A origem do conceito de formação (Bildung) ocorre no contexto histórico da ascensão política e econômica da burguesia, tal como foi observado por Theodor W. Adorno (1903-1969) da seguinte maneira:

A formação devia ser aquela que dissesse respeito — de uma maneira pura como seu próprio espírito - ao indivíduo livre e radicado em sua própria consciência, ainda que não tivesse deixado de atuar na sociedade e sublimasse seus impulsos. A formação era tida como condição implícita a uma sociedade autônoma: quanto mais lúcido o singular, mais lúcido o todo. (ADORNO, 2010, p. 13)

Essa definiçãa de Adorno sobre o conceito de Bildung se consubstancia com o próprio conceito de cidadania. Ou seja, a ontologia social do indivíduo livre e radicado em sua própria consciência se esteia na condição de que direitos e deveres sejam respeitados por todos, de tal modo que "quanto mais lúcido o singular", mais lúcido seria o todo. Justamente a lucidez do particular e, consequentemente, do todo ocorreria, uma vez que, paulatinamente, se disseminasse o chamado gérmen do esclarecimento (Aufklärung) para toda a população, tal como foi enfatizado por Kant (2005) no seu "Resposta à pergunta: o que é esclarecimento". Nesse texto, Kant conclama o indivíduo ao: Sapere aude!, ou seja, ousar saber como condição de saída de seu estado de menoridade, de indivíduo tutelado principalmente pelas regras da igreja.

Se, ao fazer uso privado de sua razão, o indivíduo estaria sujeito às imposiçóes das regras referentes aos contratos sociais das instituiçóes às quais pertenceria na esfera particular, tais como a escola e a própria igreja, já no exercício do uso público de sua razão esse mesmo indivíduo, como ser humano instruído, teria o direito e, por que não dizer, o dever de expor "publicamente suas ideias contra a inconveniência ou a injustiça dessas imposiçóes" (KANT, 2005, p. 66). Essa exposição poderia ser caracterizada como exercício de cidadania, uma vez que prevaleceria o desejo de aperfeiçoar as leis das instituiçóes que foram publicamente criticadas. Não por acaso, Kant identifica no indivíduo letrado como aquele que seria capaz de espraiar pelo mundo o chamado gérmen do esclarecimento para todas as instituiçóes sociais.

Porém, na medida em que o sistema de produção capitalista se afirmava como hegemônico política e economicamente, a defesa da universalização do conceito de cidadania encontrava um novo desmentido cada vez que o incremento das forças produtivas impingia a propagação das injustiças sociais e da exploração 
como elementos propulsores de desenvolvimento. Diante desse quadro, também a esfera da cultura gradativamente se subsume à lógica de produção e reprodução do capital, engendrando-se a mercantilizaçáo dos denominados bens culturais, cujo processo foi identificado como indústria cultural. Diante da mercantilização dos bens culturais, a própria experiência formativa torna-se prejudicada, sendo que esse processo de danificação foi caracterizado por Adorno da seguinte forma:

A experiência - a continuidade da consciência em que perdura o ainda não existente e em que o exercício e a associação fundamentam uma tradiçáo no indivíduo - fica substituída por um estado informativo pontual, desconectado, intercambiável e efêmero, e que se sabe que ficará borrado no próximo instante por outras informaçóes (...) A semiformação é uma fraqueza em relação ao tempo, à memória, única mediação capaz de fazer na consciência aquela síntese da experiência que caracterizou a formação cultural em outros tempos. (ADORNO, 2010, p. 33)

É importante observar o modo como Adorno definiu o conceito de experiência formativa. Pois a continuidade da consciência em que perdura o ainda não existe, ou seja, daquilo que está por vir, remete o pensamento a uma perspectiva futura. E essa perspectiva futura só se avizinha porque houve a religação mnemônica do indivíduo com seu passado. Seguindo essa linha de raciocínio, a expectativa da realização de algo diferente não se realiza de forma absoluta, como se fosse algo em si e por si, haja vista que se consubstancia com o passado na forma de tradiçôes presentes na tessitura identitária do indivíduo. Ao elaborar o conceito de experiência (Erfahrung), Benjamin se aproximou dessa concepção de Adorno sobre a experiência formativa, principalmente quando sublinhou que o conhecimento deriva-se da Erfahrung quando os elementos dos passados individual e coletivo se religam mnemonicamente em um presente que impele a elaboração de novas tradiçôes: "os cultos com seus cerimoniais, suas festas (...) produziam reiteradamente a fusão desses elementos [do passado individual e coletivo] da memória. Provocavam a rememoraçáo em determinados momentos e davam-lhe pretexto de se reproduzir durante toda a vida" (BENJAMIN, 1989, p. 107).

De fato, de acordo com Benjamin, esse tipo de rememoração que propicia o desenvolvimento de experiências (Erfahrüngen) é que fornece o substrato necessário para que o conhecimento derivado seja aprofundado e permaneça, ainda que transformado, na medida em que novas geraçóes se sucedam. Exatamente esse tipo de conhecimento contrasta, segundo o próprio Benjamin, com o conceito de vivência (Erlebnis), que se refere às informações pontuais e que são assimiladas às pressas. Mas é necessário destacar que essas mesmas informaçóes imediatamente vivenciadas, se forem refletidas por meio das consideraçôes das mediações históricas que delinearam seus contornos, podem se transformar em conhecimentos profundamente experienciados (ZUIN, 2011; ZUIN; PACCA, 2013). 
Contudo, precisamente esse tipo de religação histórica do indivíduo com o coletivo ao qual pertence, e que delineia um tipo de produção de conhecimento que permanece nas construçóes identitárias tanto do particular quanto do geral, é substituído por um "estado informativo pontual, desconectado, intercambiável e efêmero, e que se sabe que ficará borrado no próximo instante por outras informaçóes" (ADORNO, 2010, p. 33).

Não foi fortuita a relação estabelecida por Adorno entre a semiformação e a fraqueza em relação à memória, pois o raciocínio do indivíduo semiformado constitui-se de estereótipos que se revelam racionalizaçóes justificadoras de atitudes autoritárias e preconceituosas em relação àqueles que ousaram divergir, que se atreveram a pensar de outro modo. É por isso que se torna constante a fala do indivíduo semiformado que procura se defender da ausência da reflexão sobre as medições históricas de determinado assunto, pois não tem o tempo necessário para tal. Assim, "em lugar do temps durée, conexão de um viver em si relativamente uníssono que desemboca no julgamento, coloca-se um 'É assim' sem julgamento, algo parecido à fala dos viajantes que, do trem, dão nomes a todos os lugares pelos quais passam como um raio" (ADORNO, 2010, p. 33).

A lembrança de Adorno sobre o temps durée alude ao conceito de duração, de Henri Bergson (1859-1941). Ou seja, a possibilidade de que, da atuação da memória, origine-se um "viver em si relativamente uníssono que desemboca no julgamento" referenda a potência da reflexão do indivíduo sobre a materialidade percebida pelos sentidos. De fato, notabiliza-se, na concepção de Bergson, a forma como a duração temporal dos acontecimentos depende radicalmente da intervenção do pensamento do indivíduo. E se tal intervenção obtém esse tipo de notoriedade, torna-se imprescindível a promoção de uma espécie de educação dos sentidos: "esta educação tem por finalidade harmonizar meus sentidos entre si, restabelecer entre seus dados uma continuidade que foi rompida pela própria descontinuidade das necessidades de meu corpo, enfim reconstruir aproximadamente a totalidade do objeto material" (BERGSON, 2011, p. 49). A reconstrução mnemônica da totalidade do objeto material torna-se possível por meio da relação entre dois tipos de lembrança:

1. a que se assemelha a um tipo de hábito, de tal modo que o indivíduo se disciplina com o objetivo de aprender algo de cor;

2. a que se imprime imediatamente na memória e que concerne à representação de um acontecimento único.

Embora ambas as lembranças difiram entre si, uma vez que a primeira se constitui pela repetição e a segunda por aquilo que não se repete, Bergson as relaciona com a intenção de enfatizar a maneira pela qual conhecemos o mundo material: 
(...) e é justamente por isso que somos obrigados, para saber realmente uma coisa, para tê-la à nossa disposição, a aprendê-la de cor, ou seja, a substituir a imagem espontânea por um mecanismo motor capaz de supri-la. Mas há um certo esforço sui generis que nos permite reter (grifo nosso) a própria imagem, por um tempo limitado, sob o olhar da nossa consciência; e graças a essa faculdade náo temos necessidade de esperar do acaso a repetição acidental das mesmas situaçôes para organizar em hábito os movimentos concomitantes; servimo-nos da imagem fugaz para construir um mecanismo estável que a substitui. (BERGSON, 2011, p. 93)

Diferentemente do Proust (1871-1922) adulto que, por meio da primeira mordida no doce Madeleine saboreava sua infância, ao se religar instantânea e casualmente com seu passado, Bergson asseverava que essa religação seria conscientemente possível. Pois por meio do exercício da consciência haveria a retençáo da imagem fugaz de um acontecimento único, o que sensibilizaria o indivíduo a perceber a continuidade espaçotemporal entre os elementos de seu passado, promovendo-se, assim, a educação dos sentidos anteriormente destacada. E justamente tal retenção seria a condição sine qua non para que esse mesmo indivíduo pudesse estabelecer criticamente os julgamentos necessários afeitos às suas intervençôes no mundo material. As considerações de Bergson sobre as relaçóes entre as lembranças adquiridas pelo hábito e as espontâneas sobrelevaram a relevância da intervenção do indivíduo, fazendo com que ambas se tornassem interdependentes. Mas, e se houvesse uma sociedade cujas relaçôes de produção fomentassem uma tecnologia comunicacional capaz de fazer com que os próprios objetos desenvolvessem um tipo de memória muito mais efetiva que a de seus produtores? Nessa sociedade, na qual seria possível lembrar-se de tudo, não seriam produzidas novas formas de esquecimento? Para responder a questóes como essas, faz-se necessário refletir criticamente sobre a denominada Internet das Coisas e sua relaçáo com o processo formativo (Bildungsprozess).

\section{Internet das Coisas, vigilância, (des)memória e semiformação}

Ao desvendar o segredo do caráter fetichista da mercadoria, Marx (1818-1883), com sua ironia peculiar, afirmou que náo havia nada de misterioso no valor de uso de uma mesa, ou seja, não haveria nada de enigmático em relação ao exercício de sua finalidade enquanto objeto mesa. Entretanto, quando ela se transformava na mercadoria mesa, ela exercia tamanho sortilégio, que, por meio de sua cabeça de madeira, desenvolvia "cismas muito mais estranhas do que se ela começasse a dançar por sua própria inciativa” (MARX, 1988, p. 70).

Essa ironia de Marx fomentou o raciocínio para o modo como os consumidores reificadamente se encantavam pela sedução de quaisquer mercadorias, principalmente quando não se considerava que o caráter enigmático de tal sedução 
advinha do fato de que as mercadorias possuíam determinado valor em virtude do dispêndio de força de trabalho humana mediada na sua produção: "o misterioso da forma mercadoria consiste, portanto, simplesmente no fato de que ela reflete aos homens as características sociais do seu próprio trabalho como características objetivas dos próprios produtos do trabalho, como propriedades naturais sociais dessas coisas" (MARX, 1988, p. 71).

Sabe-se que Marx publicou sua obra seminal "O Capital: crítica da economia política" na segunda metade do século IX. Já na revolução microeletrônica do século XXI seria interessante refletir sobre as cismas referentes aos atuais objetos que não apenas dançam, mas são capazes de coletar, armazenar, reinterpretar e retransmitir as informaçōes obtidas do meio que os circunda. Essa interface comunicacional entre objetos e entre objetos e pessoas denomina-se Internet das Coisas. Ao que tudo indica, o conceito de Internet das Coisas foi primeiramente desenvolvido em 1999 por Kevin Ashton, um cientista britânico cofundador do Auto-ID Center, vinculado ao Massachusetts Institute of Technology (MIT).

A ideia principal foi desenvolver formas de comunicaçáo entre objetos, sobretudo pelo uso da chamada tecnologia de identificação por radiofrequência (RFID technology). Desse modo, os objetos que recebem as etiquetas RFID na forma de chips

são capazes de se comunicar com outros objetos devidamente etiquetados através da Internet ou de outros protocolos (...). Estes objetos podem variar desde eletrodomésticos a itens industriais, automóveis, ou mesmo comida de supermercado. Tudo pode ser etiquetado para que possa participar da Internet das coisas. (ESPADA et al., 2011, p. 24)

Se os sensores de uma geladeira, por exemplo, "percebem" que não há mais leite, é possível que a própria geladeira envie uma mensagem ao aparelho celular de seu proprietário informando-lhe sobre a necessidade de tal compra. Atualmente, já há projetos de confecção de roupas cujos sensores possibilitam a análise das temperaturas ambientes, permitindo que as próprias roupas instantaneamente se adaptem a tais condiçôes. Pacientes podem ter sensores RFID implantados por meio de chips sob a pele, de modo que possam ser ininterruptamente monitorados a distância sem que precisem comunicar pessoalmente quaisquer alteraçóes de saúde. Sendo assim, em um futuro não muito distante, pessoas propensas a sofrerem um ataque cardíaco poderiam ser localizadas e internadas em um hospital, em uma velocidade que seria decisiva para que pudessem sobreviver. Indústrias das mais variadas áreas de conhecimento poderiam se beneficiar tecnologicamente das informações continuamente renovadas por meio dessa interface entre objetos e objetos e pessoas, tais como "química, computação, física, matemática, engenharia de produção de matérias, pedagogia, arquitetura, engenharia agrícola, medicina, entre outras" (NING; HU, 2012, p. 1238). 
O espaço e a duração das brincadeiras também são ampliados de maneiras radicais, como recentemente observado na revitalizaçáo do game Pokémon $G O$ (Nintendo), que aglutina uma nação de milhóes de usuários em todo o mundo, cujo objetivo principal é a captura de "monstrinhos" do mundo virtual localizados no mundo real. Trata-se de uma realidade denominada aumentada em larga escala, que origina situaçóes inusitadas em vários campos. Quem ou o que serão as futuras celebridades ou seres populares? Quais implicações essas rupturas têm na esfera educacional, quando já podemos visualizar os contornos de entidades híbridas que já povoam e chegarão aos nossos novos e velhos mundos mediados pelos aparatos "smart-something"? (DINIZ, 2016).

Seguindo essa linha de raciocínio, desde 2011 a China se destaca mundialmente como um dos principais locus de desenvolvimento de ambientes materiais e informacionais completamente conectados pela Internet das Coisas, tais como os chamados edifícios, hospitais e casas inteligentes. Além disso, por meio dela controla-se "o monitoramento de ambientes, a segurança de minas, o gerenciamento de tickets, etc. De fato, praticamente todos os sistemas inteligentes podem ser relacionados à Internet das Coisas" (NING; HU, 2012, p. 1236). No que concerne à educaçáo, o governo chinês, por meio do Ministério da Educação, investe maciçamente não apenas na construção de instituiçôes escolares cujos ambientes são absolutamente conectados entre si por meio da comunicação de sensores RFID, como também nas estruturas curriculares de cursos tais como matemática, física, química e comunicação. A intenção é a de que a produção e a disseminação de informaçóes, provenientes do desenvolvimento das respectivas disciplinas, sejam já de antemão elaboradas de acordo com a lógica ubíqua de intercâmbio de dados viabilizado pela tecnologia da Internet das Coisas. Diante desse novo contexto, há quem já reconheça uma transformação radical na relação professor-aluno, a ponto de se afirmar que, "na era da Internet das coisas e das pessoas que se auto-orientam, a amplitude do ensinar e aprender pode ser denominada de ensinar e aprender ubíquos" (ZHANG, 2012, p. 792).

A comunicaçáo onipresente entre os mundos físico e informacional, proporcionada pela Internet das Coisas, já suscita o repensar da forma como professores elaboram estratégias didáticas em relação ao modo como as informaçóes serão apreendidas e aprendidas pelos alunos no transcorrer do processo de ensino-aprendizagem. É na sociedade da revolução microeletrônica que já se atribui a esse tipo de tecnologia a caracterizaçáo de autoridade educacional:

uma vez que o governo chinês decidiu desenvolver intensamente a Internet das coisas, o Ministério da Educação resolveu contribuir para o desenvolvimento deste tipo de Internet, que passa a ser considerada uma autoridade educacional, de tal maneira que se torna imprescindível a aplicaçáo de recursos para o treinamento de pessoal nas faculdades. (NING; HU, 2012, p. 1238) 
É interessante observar o modo como o atual desenvolvimento das tecnologias de informação e comunicação faz com que essas sejam cada vez mais identificadas como autoridades educacionais muito mais eficazes do que o próprio professor, principalmente quando se trata de exortar os alunos a se disciplinarem para que se concentrem no aprendizado dos conteúdos das mais variadas matérias. A presença de câmeras nas salas de aula cumpre muito bem tal função de disciplinar não só os alunos, como também os professores, sendo que ambos se transformam em caricaturas de si mesmos, pois, na condição de atores, representam seus papéis para plateia que os assiste por meio da transmissáo on-line de suas imagens e sons. Assim, por trás da justificativa dos diretores das instituiçóes escolares de que, graças às câmeras, os pais podem acompanhar o aprendizado de seus filhos em quaisquer tempos e espaços, o chamado panóptico eletrônico permite fazer com que a própria autoridade do professor seja subsumida à da câmera.

De fato, há uma ruptura significativa em relação à autoridade do professor, identificado como figura decisiva para o progresso formativo do aluno. Ao comentar a importância da autoridade, Adorno asseverou que, náo obstante os vários conflitos decorrentes do confronto do aluno ou do filho com as figuras paternas e do professor, a mediação da autoridade de ambos era de fundamental importância para a emancipação do aluno ou do filho, pois: "a formação desenvolvia-se socialmente da mesma maneira como, segundo Freud, a autonomia, o princípio do ego, brota da identificação com a figura paterna, ao passo que as categorias a que se chega por intermédio desta se voltam contra a irracionalidade das relaçóes familiares" (ADORNO, 2010, p. 21).

Historicamente, o processo de internalização da autoridade por parte do aluno vinculou-se à internalizaçáo da disciplina, para que, gradativamente, pudesse se voltar conscientemente contra as irracionalidades tanto das relaçóes familiares quanto das estabelecidas com os professores. Contudo, na sociedade da cultura digital, há uma tendência cada vez mais presente de que a disciplina seja obtida por meio da vigilância ininterrupta e ubíqua das câmeras instaladas nos ambientes escolares (ZUIN, 2012).

Não será surpresa se, em tempos da disseminação da Internet das Coisas, houver a defesa de outro tipo de internalização de normas disciplinares: a introdução subcutânea de sensores RFID nos corpos dos alunos, de tal maneira que possam ser vigiados o tempo todo dentro e fora das instituiçóes escolares. Assim, ao invés de se fomentar o processo de consciência crítica do aluno, que gradativamente reconhece a importância do esforço disciplinar de se concentrar nos conteúdos para que possa aprendê-los, promove-se uma situação na qual a consciência moral é como que substituída pelo temor de ser exposto por meio das imagens captadas pelas tecnologias ubíquas de informação e comunicação. Diante desse contexto, cabe a pergunta: que tipo de consciência moral pode se desenvolver na sociedade que impóe a vigilância absoluta? Embora o espectro de vigilância das tecnologias de informação e comunicação, 
tais como as câmeras, seja amplamente conhecido, não há como ser comparado com o potencial de vigilância da Internet das Coisas em virtude dos seguintes aspectos:

1) Os sensores estáo se tornando cada vez menores, de tal modo que, com os avanços da nanotecnologia, não se sabe como e quando as informaçôes de quaisquer pessoas estáo sendo coletadas; 2) Consequentemente, bilhóes de objetos do cotidiano podem ser equipados com tais sensores, fazendo com que novos tipos de dados sejam amealhados e 3) Uma vez que os dados coletados façam parte de um sistema de rede globalizado, eles podem ser potencialmente agregados a outras informaçóes pessoais registradas a qualquer momento. (WINTER, 2014, p. 28)

Diante de tamanho potencial de captura de dados pessoais, evidentemente as crianças se tornam um dos principais alvos de acordo com os mais variados propósitos. Por exemplo, empresas cujos brinquedos equipados com sensores fornecem vários tipos de dados sobre quando e como elas interagem com eles, o que possibilita a obtenção de dados de pacientes infantis, reduzindo significativamente a ansiedade que se faz presente por ocasiáo da aplicação de exames médicos tradicionais. Esse é o caso do brinquedo Teddy, the guardian, que, ao interagir com pacientes infantis, torna-se apto a fornecer aos médicos, em tempo real, informaçôes sobre a "frequência cardíaca, a saturação de oxigênio, a temperatura do corpo e o nível de stress" (MANCHES et al., 2015, p. 77).

De certo modo, há de se reconhecer que essa capacidade da própria Internet de armazenar e transformar as informaçóes torna-se decisiva para a revitalização do atual sentido da formação. E isso acontece quando tais informaçóes se transformam em objetos da intervençáo humana que estimula o senso de continuidade entre tais dados e, principalmente, entre os indivíduos que os refletem, mesmo quando tais pessoas encontram dificuldades em estabelecer esses vínculos emocionais e informacionais. Esse é o caso dos pacientes de Alzheimer que, por meio das histórias registradas em seus lifelogs, ou seja, do intercâmbio de informaçóes que se modificam continuamente, estabelecem entre si esse senso de continuidade de tal maneira, que "o lifelog se torna literalmente um aparelho mnemônico através do qual tais pacientes podem falar sobre o que pensam, mesmo quando os estados mentais parecem se tornar cada vez mais confusos aos olhos dos parentes que os amam" (VAN DIJK, 2007, p. 75).

Mas, se tais informaçóes pessoais são coletadas todo o tempo com vistas a hegemonicamente recrudescer o capital e o poderio militar, ou mesmo de ambos concomitantemente, há o reconhecimento de que, com a expansão da Internet das Coisas, encontra-se em curso uma "transformação inaudita na natureza (ontológica), do ambiente informacional” (FLORIDI, 2005, p. 186). Essa posição também é compartilhada por Shaev, ao afirmar que, na era da Internet das Coisas, é preciso refletir filosoficamente a respeito do fato de que: 
(...) o espaço que envolve o ser humano e o mundo das coisas adquire contornos ontológicos. Isso não significa que as pessoas são reduzidas ao nível dos objetos, das coisas. Pelo contrário, as próprias coisas obtém uma especificidade ontológica distinta e se aproximam cada vez mais do ser humano. (SHAEV, 2014, p. 877)

$\mathrm{Na}$ verdade, essa nova ontologia precisa ser socialmente compreendida não como algo que baste a si próprio. Pois o caráter social da Internet das Coisas, presente nas relaçóes de trabalho e nas do chamado tempo livre, encontra-se imanentemente mediado nos objetos habilitados a coletar, armazenar, transformar e transmitir informaçóes de forma inédita. Exatamente essa capacidade redimensiona o ambiente informacional de tal maneira, que há outro aspecto, além da relação entre disciplina e vigilância, sendo completamente reconfigurado e que é de fundamental importância para o desenvolvimento do processo de ensino-aprendizagem: a memória.

Sabe-se que, nos tempos da cultura digital, torna-se praticamente impossível se esquecer de alguma informação. Caso haja quaisquer dúvidas em relação a qualquer tipo de assunto, basta digitar as palavras-chave nos mecanismos de busca que os algoritmos dos softwares do Google, por exemplo, se encarregarão de localizá-las imediatamente. Não por acaso, os alunos o homenageiam nas cerimônias de suas formaturas ao estenderem faixas com os seguintes dizeres: "Obrigado, Google, sem você eu não teria me formado". Essa ironia dos alunos diz muito sobre a atual cultura digital, haja vista o fato de que o esforço humano da memorização dos conteúdos parece estar em processo de absoluta decadência. A respeito de tal esforço, já no final da década de 1950, Adorno apresentava-nos as seguintes consideraçóes:

Quem tendo frequentado a escola não terá se emocionado alguma vez com a poesia de Schiller e os poemas de Horácio que devia aprender de cor? (...) Com certeza, dificilmente se pediria hoje que alguém aprendesse algo de cor: apenas pessoas muito ingênuas estariam dispostas a apoiar-se na tolice e na mecanicidade deste processo; porém, assim se priva o intelecto e o espírito de uma parte do alimento de que se nutre a formação. (ADORNO, 2010, p. 21-22)

Talvez essa emoção descrita por Adorno resultasse do esforço de memorizar os conteúdos dos versos de Schiller e Horácio, sendo que o olhar de satisfação do professor certamente compensaria a lida do aluno em decorar tais versos. Ou então tamanha energia mental dispendida decorreria do receio do mesmo aluno de receber o olhar de desaprovação do professor. De um modo ou de outro, o professor era identificado como uma autoridade educacional determinante para a elaboração da estrutura identitária do aluno, tal como foi mencionado. 
Nesse mesmo texto, Adorno reconhece o papel fulcral das reformas pedagógicas que avultaram a necessidade de se considerar cada vez mais os interesses dos alunos em relação às matérias de estudo. Todavia, esse pensador frankfurtiano também admite que, apesar da mecanicidade do processo de se exigir do aluno a memorização de determinados conteúdos, o arrefecimento dessa exigência, decorrente de tais reformas, privou o "intelecto e o espírito de uma parte do alimento de que se nutre a formação" (ADORNO, 2010, p. 22). Evidentemente, Adorno estava se referindo à importância do empenho de se religar mnemonicamente com o passado representado nos versos e, portanto, com a possibilidade de que esse mesmo aluno se sensibilizasse a ponto de transformar suas relaçóes presentes e futuras. Mas Adorno, ao afirmar a relevância da capacidade de memorização consubstanciada à sensibilização, era partícipe de um tempo no qual tal relação ainda dependia da intervenção do indivíduo para que pudesse ser realizada. Se estivesse ainda vivo, o que ele diria de uma sociedade cujos objetos coletam, memorizam, transformam e transmitem as informaçóes que os circundam para outros objetos e pessoas, bem como entidades híbridas?

É nessa sociedade da cultura digital que, em relação à obtenção e à memorização de quaisquer tipos de informação, o "onde" se torna cada vez mais importante do que o "o quê". Ou seja, saber localizar determinadas informaçóes por meio da escolha das palavras-chave que acionarão os algoritmos do software de buscas do Google se torna mais relevante do que o entendimento dos significados dessas respectivas informaçóes (SPARROW; LIU; WEGNER, 2011). Consequentemente, na sociedade na qual se torna tecnologicamente possível lembrar-se de tudo, novas formas de esquecimento são engendradas. Casos de indivíduos que são sumariamente julgados e condenados em função de imagens e comentários segmentados postados nas redes sociais pululam com frequência cada vez maior. Um desses casos paradigmáticos ocorreu com um psicólogo canadense de 60 anos, que em 2006 foi receber um amigo no Aeroporto Internacional de Seattle-Tacoma, nos Estados Unidos da América. Esse psicólogo já havia recebido amigos nesse aeroporto em várias ocasióes. Porém, dessa vez um funcionário da alfândega resolveu digitar o nome dessa pessoa no mecanismo de busca de um site da Internet e descobriu que ele havia sido detido em 1960 com uma pequena quantidade de LSD. Após ser interrogado por quatro horas, ele foi fichado e assinou um documento no qual admitia que fora detido em uma apreensáo policial na década de 1960. Após esse procedimento, o psicólogo tornou-se impedido de entrar nos EUA, sob o risco de ser preso caso descumprisse essa imposição judicial (SCHÖNBERGER, 2009).

A condenação judicial desse psicólogo pautou-se na absolutização atemporal de sua imagem, como se os 46 anos que separavam sua detenção em 1960 e seu julgamento sumário não mais existissem; como se o contexto histórico no qual fora detido portando LSD simplesmente pudesse ser ignorado diante da etiqueta de possível traficante que lhe foi imposta em 2006. Não por acaso, Galloway lem- 
bra-nos que, em determinadas situações, "o virtual só pode ser possível não em relação ao real, mas sim ao absoluto" (GALLOWAY, 2012, p. 124), haja vista que o pensamento-reflexivo se converte no pensamento-reflexo que se nutre de indefectíveis estereótipos e rótulos.

É por isso que novas formas de esquecimento são produzidas na sociedade na qual se pode tecnologicamente lembrar-se de tudo, principalmente quando os absolutos se impóem sobre as tessituras históricas que os produziram. E quando tais absolutos se impóem recrudesce o discurso que defende a neutralidade dos educadores praticada nas atividades do processo de ensino-aprendizagem. Exatamente essa proposta de neutralidade se afina eletivamente com a chamada Escola sem Partido ${ }^{1}$, mediante a qual os professores transmitiriam os dados aos seus alunos de forma neutra, como se isso fosse possível. Nesse tipo de escola, o professor deixaria de se posicionar criticamente sobre determinado tema, o que arrefeceria o próprio debate de ideias consigo e com seus alunos. Não haveria tempo nem espaço para que o professor assumisse, diante dos alunos, uma determinada posição que deveria potencializar o confronto respeitoso de opinióes, e náo ser considerada pelo alunado como a única interpretaçâo correta da temática em pauta. No contexto da Internet das Coisas, o professor, como transmissor supostamente neutro de dados, se apropriaria da história desses nos objetos de forma absolutamente a-histórica, o que suscitaria um terreno fértil para vicejar o pensamento estereotipado e o preconceito. Pois tal apropriação seria apartada da discussão das contradiçóes humanas que a engendraram. Será que, diante desse quadro, também os professores permanecerão futuramente atrelados às etiquetas não só dos sensores de RFID dos objetos, como também da nova mentalidade do ticket, para usar uma expressão de Adorno (1972), quando acessarem quaisquer informaçóes e as transmitirem para seus alunos de forma superficial, estereotipada e supostamente neutra?

\section{Conclusão}

A Internet das Coisas representa um novo momento revolucionário na história da humanidade, sendo que os efeitos de tal transformação já começam a ser visualizados nas mais variadas esferas, inclusive a educacional. Os mundos material e informacional que se fundem, por meio da interface comunicacional entre objetos e objetos e pessoas, proporcionam o acesso aos dados de uma forma inédita na história da produção tecnológica. Ou seja, atualmente existe a tecnologia que nos possibilita contactar não somente a origem da produção de objetos e relaçôes humanas, como também os respectivos históricos de transformaçóes, na medida em que interagem com outros objetos e pessoas. Em termos benjaminianos, são incomensuráveis as vivências possíveis de, qualitativamente, se tornarem experiências, ou seja, conhecimentos cada vez mais criticamente refletidos e aprofundados. Ou então, em termos adornianos, são incontáveis as informaçóes que 
podem deixar de se aferrar a um estado pontual e efêmero para que se metamorfoseiem em experiências formativas amparadas por conhecimentos que permaneçam na consciência, a ponto de suscitarem a presença do ainda não existente. De certo modo, Bergson também exaltou a importância de que as imagens perdurassem na consciência, de modo que deixassem de ser fugazes e se transformassem em hábito engendrando, portanto, conhecimento.

Mas, nos tempos atuais, parece prevalecer exatamente a tendência contrária a essa possibilidade de elaboração emancipatória do conhecimento. Tal como foi anteriormente asseverado, a semiformação implica em um estado de fraqueza em relação à memória. Então, isso implica que, na sociedade da Internet das Coisas, não existiria mais a semiformação, já que o esquecimento se torna praticamente impossível? Ao que tudo indica, paradoxalmente, a semiformaçáo se reforça exatamente no seu extremo oposto. A atual disseminação do pensamento estereotipado se alicerça na contínua recuperação mnemônica de imagens e comentários eternizados nas redes sociais, como se fossem absolutos completamente apartados dos contextos históricos em que foram produzidos, armazenados, transformados, transmitidos e ressignificados.

Ora, justamente a tecnologia da Internet das Coisas, na condição de força produtiva humana, possibilita-nos acessar a história da hospedagem e da transformação das informações, a ponto de presencialmente nos religarmos com os espaços e tempos de nosso passado e, assim, projetarmos perspectivas de novos futuros. Mas é preciso que haja a concentração necessária para que a informaçáo pontual se converta em conhecimento profundo, sendo essa uma possibilidade cada vez mais difícil na sociedade na qual o déficit de atenção não pode ser adjudicado exclusivamente às idiossincrasias de um indivíduo. Pois se torna manifestação de uma cultura, a cultura do déficit de atenção, um vislumbre de tudo no nada (TÜRCKE, 2012).

Justamente nessa cultura do déficit de atenção, a posição do professor se torna imprescindível para que possa, com seus alunos, reter a informação audiovisual obtida pelos sensores RFID, de modo que haja o tempo necessário para a sua conversão qualitativa em conhecimento, produzindo-se, assim, novos conceitos. A atual preferência pelo "onde", quando se torna necessário encontrar as informaçôes desejadas nos mais variados sites de busca, precisa ser criticamente relacionada com o "quando" e o "como". Se isso for feito, há uma possibilidade de que se compreenda criticamente "o quê", ou seja, o significado das histórias de tais informaçóes e das relaçôes estabelecidas entre si e seus produtores. É dessa forma que o conceito de formação se revitaliza no tempo e no espaço da Internet das Coisas. Seguindo essa linha de raciocínio, Hayles afirma que o grande desafio que a tecnologia RFID atualmente nos apresenta é o de "como usá-la para repensar a subjetividade humana numa forma construtiva e emancipatória, sem capitular aos seus aspectos coercitivos e exploratórios" (HAYLES, 2009, p. 48). 
O uso emancipatório de tal tecnologia se torna possível se houver a crítica do fetiche da própria Internet das Coisas, pois o caráter social presente nos seus aspectos coercitivos e exploratórios é produto do trabalho humano e, portanto, passível de ser transformado. Sendo assim, na esfera educacional, na medida do possível, professores e alunos podem, juntos, acessar o histórico das informaçóes propiciado pelos sensores RFID não para que, como novos Funes, tenham sua memória vertida em despejadouro de lixo, mas para que a utilizem como capacidade humana tecnologicamente ampliada que lhes assessorem a lembrar criticamente de suas intervençóes na história passada e na que está por vir.

\section{Notas}

1. Os autores deste artigo agradecem a sugestão de Ivany Rodrigues Pino de associar o tema da Internet das Coisas com a Escola sem Partido.

\section{Referências}

ADORNO, T.W. Studies in the authoritarian personality. In: ADORNO, T.W. Gesammelte Schriften 9- Soziologische Schriften II - Erste Hälfte. Frankfurt am Main: Suhrkamp Verlag, 1972. p. 143-508.

ADORNO, T.W. Teoria da semiformação. In: PUCCI, B.; ZUIN, A.A.S.; LASTÓRIA, L.A.C.B. (Orgs.). Teoria critica e inconformismo: novas perspectivas de pesquisa. Campinas: Autores Associados, 2010.

BENJAMIN, W. Charles Baudelaire: um lírico no auge do capitalismo - obras escolhidas III. São Paulo: Brasiliense, 1989.

BERGSON, H. Matéria e memória: ensaio sobre a relação do corpo com o espírito. São Paulo: Martins Fontes, 2011.

BORGES, J.L. Obras completas, volume I. Vários tradutores. São Paulo: Globo, 2000.

DINIZ, A.M. Pokemón Go e a educação: preparem-se, muita coisa irá mudar. Disponível em: $<\underline{\text { http://educacao.estadao.com.br/blogs/ana-maria-diniz/pokemon-go-e-educacao-preparem- }}$ se-muita-coisa-vai-mudar/>. Acesso em 25 jul. 2016.

ESPADA, P.J.; MARTINEZ, O.S.; GARCIA-BUSTELO, B.C.P.; LOVELLE, J.M.C. Virtual objects on the Internet of things. International Journal of Artificial Intelligence and Interactive Multimedia, v. 1, n. 4, p. 24-30, 2011.

FLORIDI, L. The ontological interpretation of informational privacy. Ethics Information Technology, v. 7, n. 4, p. 185-200, dez. 2005.

GALLOWAY, A.R. The interface effect. Cambridge: Polity Press, 2012.

HAYLES, K.N. RFID: human agency and meaning in information-intensive environments. Theory, Culture \& Society, v. 26, n. 2-3, p. 47-72, 2009. 
KANT, I. Resposta à pergunta: que é esclarecimento. In: KANT, I. Textos seletos. Petrópolis: Vozes, 2005.

MANCHES, A.; DUNCAN, P.; PLOWMAN, L.; SABETI, S. Three questions about the Internet of things and children. TechTrends, v. 59, n. 1, p. 76-83, jan. 2015.

MARX, K. O capital, volume 1. São Paulo: Nova Cultural, 1988.

NING, H.; HU, S. Technology classification, industry and education for future Internet of things. International Journal of Communication Systems, v. 25, n. 9, p. 1230-1241, set. 2012.

SCHÖNBERGER, V.M. Delete: the virtue of forgetting in the digital age. Princeton: Princeton University Press, 2009.

SHAEV, Y. From the sociology of things to the "Internet of things". Procedia-Social and Behavioral Sciences, v. 149, p. 874-878, set. 2014.

SPARROW, B.; LIU, J.; WEGNER, D.M. Google effects on memory: cognitive consequences of having information at our fingertips. Science, v. 333, n. 6043, p. 776778, ago. 2011.

TÜRCKE, C. Hyperaktive! Kritik der Aufmerksamkeits Defizit Kultur. München: Verlag C.H.Beck, 2012.

VAN DIJCK, J. Mediated memories in the digital age. Stanford: Stanford University Press, 2007.

WINTER, S.J. Surveillance in ubiquitous network societies: normative conflicts related to the consumer in-store supermarket experience in the context of the Internet of Things. Ethics and Information Technology, v. 16, n. 1, p. 27-41, mar. 2014.

ZHANG, T. The Internet of things promoting higher education revolution. Fourth International Conference on Multimedia Information Networking and Security, Guangzhou,vol.1, p.790-793, 2012.

ZUIN, V.G. A inserção da dimensão ambiental na formação de professores de Química. $1^{\mathrm{a}} \mathrm{ed}$. Campinas: Átomo, 2011.

ZUIN, A.A.S. Violência e tabu entre professores e alunos: a Internet e a reconfiguração do elo pedagógico. São Paulo: Cortez, 2012.

ZUIN, V.G.; PACCA, J.L.A. Formación docente en química y ambientación curricular: estudio de caso en una institución de enseñanza superior brasilera. Enseñanza de las Ciencias, v. 31, n. 1, p. 77-91, 2013.

Recebido em 28 de julho de 2016.

Aprovado em 18 de agosto de 2016. 